\title{
Differences in influence between pitched- from-vertical lines and slanted-from-frontal horizontal lines on egocentric localization
}

\author{
WENXUN LI and LEONARD MATIN \\ Columbia University, New York, New York
}

\begin{abstract}
The visual field exerts powerful effects on egocentric spatial localization along both horizontal and vertical dimensions. Thus, (1) prism-produced visual pitch and visual slant generate similar mislocalizations of visually perceived eye level (VPEL) and visually perceived straight ahead (VPSA) and (2) in darkness curare-produced extraocular muscle paresis under eccentric gaze generates similar mislocalizations in VPEL and VPSA that are essentially eliminated by introducing a normal visual field. In the present experiments, however, a search for influences of real visual slant on VPSA to correspond to the influences of visual pitch on VPEL failed to find one. Although the elevation corresponding to VPEL changes linearly with the pitch of a visual field consisting of two isolated $66.5^{\circ}$ long pitched-from-vertical lines, the corresponding manipulation of change in the slant of either a horizontal two-line or a horizontal four-line visual field on VPSA did not occur. The average slope of the VPEL-versus-pitch function across 5 subjects was +0.40 over a $\pm 30^{\circ}$ pitch range, but was indistinguishable from 0.00 for the VPSA-versus-slant function over $\mathrm{a} \pm 30^{\circ}$ slant range. Possible contributions to the difference between susceptibility of VPEL and VPSA to visual influence from extraretinal eye position information, gravity, and several retinal gradients are discussed.
\end{abstract}

The egocentric localization of objects within a visual field may be specified relative to two visual norms: visually perceived eye level (VPEL) and visually perceived straight ahead (VPSA). VPEL is the set of visual directions that one perceives as being at the level of one's eyes; VPSA is the set of visual directions that one perceives as coincident with one's midsagittal plane. Specifying the location of an object relative to both VPEL and VPSA is sufficient to localize the perceived visual direction of the object relative to oneself.

The coordinate relations of an object's visual direction with respect to the two norms within a frontal plane are symmetric. ${ }^{1}$ The geometrical symmetry under $90^{\circ}$ rotation is intuitively clear, as in the representation in Figure 1. For central projection on a spherical approximation to the eye, all members of a parallel line set in physical space are imaged on great circles that intersect at two points $180^{\circ}$ apart. Thus, for viewing in primary position, the set of pitched-from-vertical lines intersect at two points on the central vertical retinal meridian (CVRM); the intersection points on the CVRM are at the two poles for a vertical set and change linearly with changes in the angle of pitch of the visual field. ${ }^{2}$ Similarly, the images of parallel horizontal line sets intersect

The research was supported by Grants 91-0146 and F49620-94-10397 from the Air Force Office of Scientific Research. An abbreviated report of this study was presented in $\mathrm{Li}$ and Matin (1993b). Correspondence should be addressed to W. Li, Department of Psychology, Columbia University, New York, NY 10027 (e-mail: w118@) columbia.edu). at two points on the equator of the eye. For the eye viewing a set of horizontal lines in a frontoparallel plane, the intersection points of the great circles containing the images of the lines lie at the left and right poles of the spherical approximation to the eye (Figure 1, central panel); changes of the slant (see Note 2) of the plane containing the lines result in linear changes of the intersection points along the equator (Figure 1, left and right panels).

The simple symmetry between the changes in the central projections of the line stimulus onto the eye as the visual field undergoes pitch and slant is complemented by the results of several previous experiments. These experiments have measured symmetrical influences of the visual field on the VPSA and VPEL discriminations:

(1) Prism-produced rotations of the visual field around vertical and around horizontal axes lead to essentially identical perceptual consequences for VPSA and VPEL along the horizontal and vertical dimensions, respectively. However, the consequences of the introduction of prisms are quite different in darkness and in an illuminated visual field. The localization errors made by normal subjects viewing monocularly in total darkness approximate the optical rotation introduced by the wedge prism when setting VPSA (prism base-left or base-right) or when setting VPEL (prism base-up or base-down). But the magnitude of the mislocalization for each prism orientation is only one third of the prismatically produced rotation when the settings are made while the subjects view a normally structured visual field along with the introduction of the prism (Rock, Goldberg, \& Mack, 1966). 


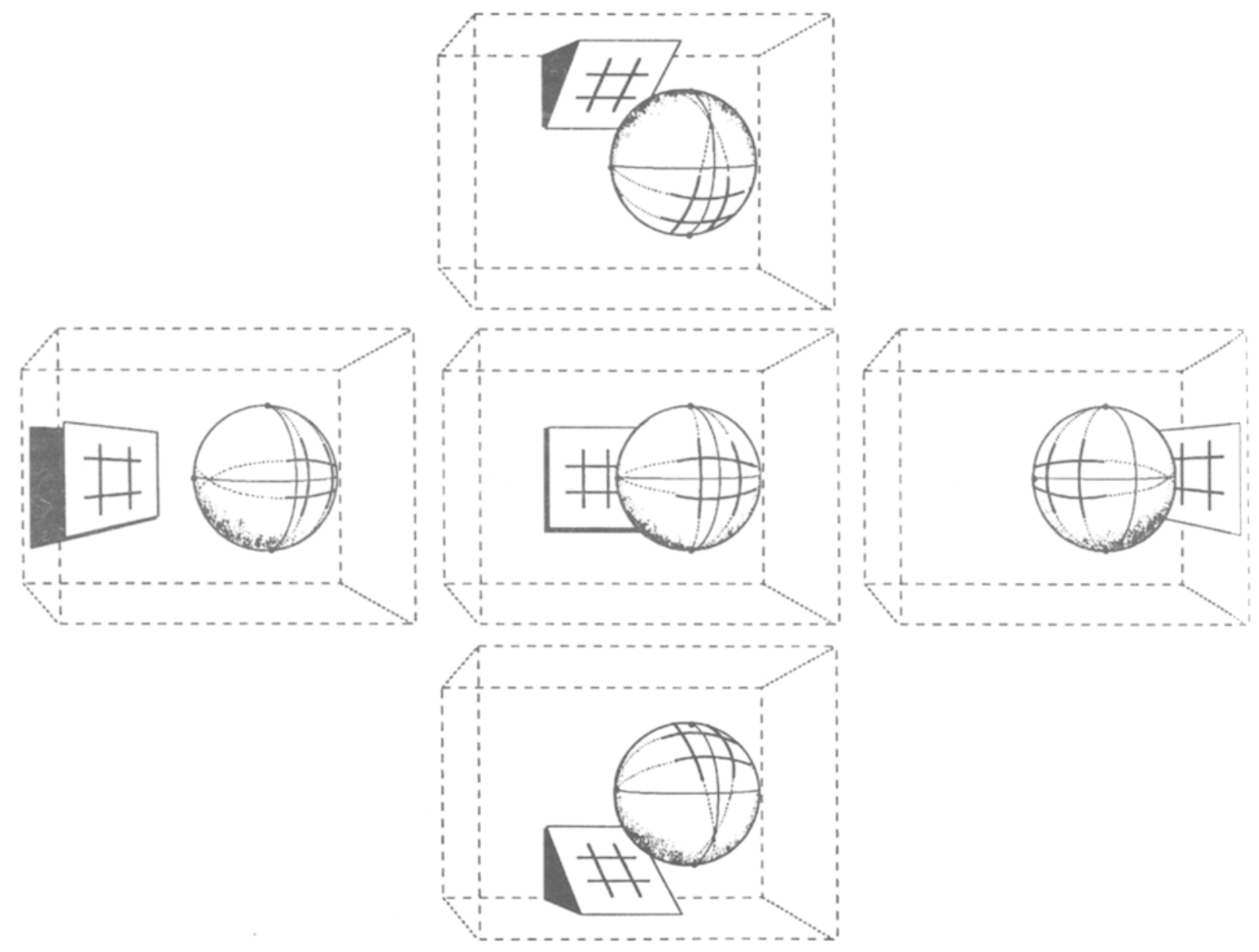

Figure 1. Five sketches of a projection sphere ("spherical approximation of an eye") viewing a reduced grid consisting of crossed two-line pitched-from-vertical and slanted-from-frontal horizontal stimuli. The image at the back of the eye results from central projection thmugh the pinhole pupil at the center of the sphere. The figures are not drawn to scale; the perspective is intended to display clearly only certain features of the relation between stimulus and image. The eye is in the same fixed position in the "room" in the five panels. The front of the eye with its pinhole pupil faces the center of the stimulus in the central panel and remains in the same fixed orientation relative to the room in the other four panels; the fixity of eye orientation is indicated by the three dark dots at the top, bottom, and left side of the sphere; the dots represent the top and bottom poles on the vertical axis of the sphere and the left pole of the horizontal axis within a frontal plane through the center of the sphere, respectively. The equator and central vertical meridian on the surface of the back of the sphere (the retina) are shown by light solid curves in the three panels. The figure shows the image of the stimulus as if it is visible from outside the sphere. The grid stimulus in the central panel is in a frontoparallel plane. In the bottom panel, it is pitched "topbackward" anound an axis coincident with the axis of the eye through the left and right poles; in the upper panel, the stimulus is rotated "topforward." In the left panel, it is slanted leftward around an axis coincident with the axis of the eye through the upper and bottom poles; in the right panel, the stimulus is rotated rightward. Thus, the normal from the nodal point of the eye extends to the center of the plane containing the grid in each of the five panels, and the distance along the normal is constant. We call attention to the fact that the axes for pitch and slant in the figures are centered on the eye, whereas the axes in the present experiments are centered in the plane of the stimulus.

(2) Subjects whose extraocular muscles are partially paralyzed with curare make similar gaze-dependent errors in setting a visual target to VPEL and to VPSA in darkness for changes in gaze direction from a primary viewing position that are similar for vertical and horizontal ocular deviations, respectively (Matin et al., 1982; Matin, Stevens, \& Picoult, 1983). For VPEL and VPSA, the mislocalizations are linear with the magnitude of the ocular deviation. However, the mislocalizations in VPEL and VPSA of the partially curarized subjects are virtually eliminated on exposure to a normally illuminated structured visual field. Thus, corresponding experimental manipulations of the visual field related to the two different spatial dimensions again produce closely similar consequences for perception.

More recently it has been shown that the physical elevation of an individual's VPEL changes linearly with the visual pitch of an illuminated structured visual field (Matin \& Fox, 1986, 1989, 1990; Matin \& Li, 1989b, 1991, 1992a, 1992b, 1994a, 1994b; Matin, Li, \& Doktorsky, 1988; Stoper \& Cohen, 1989). Deviations from true eye level average more than 0.6 times the angle of pitch over the pitch range examined from $-40^{\circ}$ (top of the visual field turned away from the observer) to $+25^{\circ}$ 
(top of the visual field turned toward the observer). The fact that the slope of the VPEL-versus-pitch function is less than +1.00 , along with the fact that VPEL in complete darkness typically does not deviate by more than $6^{\circ}$ from true eye level (Hoppeler, 1913; MacDougall, 1903; Matin, 1986; Matin \& Fox, 1986, 1989; Matin et al., 1982; Sharp, 1934; Stoper \& Cohen, 1986), has made it clear that the determination of VPEL in the presence of a pitched visual field is not a consequence of the visual field alone but of the weighted combination of influences from the visual field and from a body-referenced mechanism. The body-referenced mechanism itself integrates inputs from extraretinal eye position information (EEPI), extraretinal head orientation information, and information regarding retinal location of the target (Matin, 1986; Matin \& Li, 1992b).

The influence of the pitched visual field on the elevation of VPEL has been shown to depend on the retinal orientation of individual pitched-from-vertical lines (Matin \& Li, 1990, 1992a, 1992b, 1994a, 1994b). Thus, the effect on VPEL of pitching a field consisting of only two isolated vertical lines in darkness is more than four fifths as large as that of pitching a complexly structured visual field (Matin, Fox, \& Doktorsky, 1987; Matin \& Li, 1989b, 1992a, 1992b, 1994a), and the influence of a visual field consisting of only a single pitched-fromvertical line is not much less (Matin \& Li, 1989b, 1990, 1994a, 1994b).

This influence on VPEL of individual pitched-fromvertical lines as well as fully structured visual fields has been treated by the great circle model (GCM; Matin \& Li, 1992a, 1992b, 1994a, 1994b). GCM accounts well for all of the presently available facts regarding the visual influence on VPEL. These include the following: (1) summation among distant pitched-from-vertical lines is as great as among coextensive segments (Matin \& Li, 1989a, 1994b), (2) an oblique line in a frontoparallel plane has the same effect on VPEL as does a pitchedfrom-vertical line in a pitched-only plane that stimulates the identical retinal locus (Matin \& Li, 1990, 1992a; in press), and (3) the influences of simultaneously presented lines of different retinal orientations follow an averaging rule (Li \& Matin, 1992; Matin \& Li, in press). The geometric properties of projection of stimulus lines on the retina are particularly simply dealt with by GCM (Matin \& Li, 1992b, 1994a, 1994b) and lead to a plausible and simple neurophysiological interpretation (Matin $\& \mathrm{Li}, 1994 \mathrm{a}, 1994 \mathrm{~b})$. Since GCM is built on geometric properties that are themselves symmetric for the horizontal and vertical dimensions (Figure 1), it also would permit a symmetric development for an influence of slant on VPSA.

The symmetry of the relations in Figure 1 of the mislocalizations induced by prisms and by experimentally induced partial paralysis of the extraocular muscles suggests that the processes of egocentric localization might also be symmetrical with respect to the two norms. The success of GCM, along with the large variation in the elevation of VPEL produced by variation of pitch of a vi- sual field consisting of only two vertical lines, has encouraged us to examine whether rotating a visual field consisting of only two horizontal lines around a vertical axis would produce the symmetrical result-changes in VPSA systematically related to visual slant.

Employing a two-line stimulus instead of a more natural visual field has other virtues: Presenting it in separate conditions in slanted-from-frontal and pitchedfrom-vertical orientations eliminates nonsymmetric differences for slant and pitch that would be part of any natural visual field but would be artifactual in the present context where comparisons between the influences on VPSA and VPEL are of primary concern. In addition, a considerable body of work has made it clear that the retinal orientation of pitched-from-vertical line stimuli is the key to the influence on the VPEL discrimination with more complex natural visual fields.

The present report describes four experiments whose main purpose was to determine whether this symmetry in effect on egocentric localization holds for the visual field consisting of the two-line stimulus in darkness. The first three experiments described below are concerned with whether the slanted-from-frontal visual field consisting of horizontal lines only influences VPSA in a fashion similar to the way in which the two-line pitchedfrom-vertical stimulus influences VPEL. When the first three experiments failed to yield any indication of changes in VPSA, we carried out a fourth experiment to check on the possibility that vertical lines, which generated the influence on VPEL when their plane was pitched, might also generate an influence on VPSA when their plane was slanted. Again, however, no influence was obtained.

\section{METHOD}

\section{Stimulus Display}

The visual display consisted of individual strips of phosphorescent tape that had received a brief exposure $(2 \mathrm{~min})$ to normal room illumination prior to each experimental run. Each strip was $144 \times 0.2 \mathrm{~cm}$, with a luminance of $0.01 \mathrm{ml}$ (EG\&G photometerradiometer 550). Each strip was attached to the central section of a separate plastic bar that was painted flat black and was itself at tached to one of two similarly modified free-standing blackboards $(154 \times 104 \mathrm{~cm})$ by means of Velcro. One of the blackboards was employed for presentation of the pitched stimulus in Experiment 1; the second blackboard was employed for presentation of the slanted stimuli in Experiments $1-4$. At the 1 -m viewing distance, with the blackboard set to an erect orientation in the frontoparallel plane of the subject, each of the two strips subtended $66.5^{\circ}$ $\times 5.6^{\prime}$ visual angle in either the vertical or the horizontal position employed in the first and fourth experiments. In the second experiment, each of the two strips subtended a larger visual angle, $69.6^{\circ} \times 6.4^{\prime}$, by virtue of its reduced vertical eccentricity. In the third experiment, where four horizontal strips were employed, two subtended $66.5^{\circ} \times 5.6^{\prime}$ and the other two subtended $69.6^{\circ} \times 6.4^{\prime}$.

For each angle of pitch of the vertical two-line stimulus, the blackboard was rotated around a horizontal axis through the midpoint of the two parallel lines that was fixed at the height of the subject's true eye level. For each angle of slant of the horizontal two-line or four-line stimulus, the blackboard was rotated around a vertical axis through the midpoint of the parallel horizontal lines that was fixed in the median plane of the subject. For each angle 


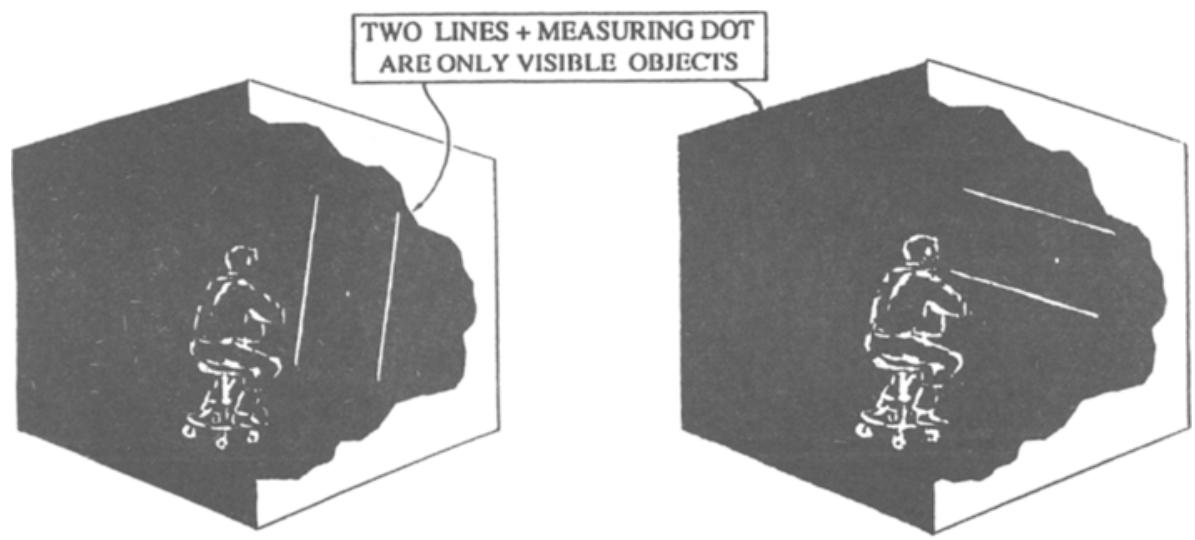

(a)

(b)

Figure 2. (a) Sketch of the subject viewing the vertical two-line stimulus pitched "topbackward" (top away from observer). The two luminescent strips $(0.2 \times 144 \mathrm{~cm})$ were attached to two black plastic bars, which were themselves attached to a specially modified blackboard $(154 \times 104 \mathrm{~cm})$ by Velcro. The point between the two strips on the blackboard facing the observer indicates the terminus of the laser beam that was set by the observer's instruction to visually perceived eye level (VPEL). (b) Sketch of the horizontal two-line stimulus slanted "rightbackward" (right side away from observer). The point between the two strips indicates the terminus of the laser beam that was set by the observer's instruction to visually perceived straight ahead (VPSA). In all cases, the room was completely dark, with the exception of the twoline stimulus and the target set to either VPEL or VPSA.

of slant of the vertical two-line stimulus in Experiment 4, the two lines were symmetrically located around the axis of rotation, which was again in the median plane of the subject. In all cases, the distance of the blackboard to the subject was adjusted so that the normal visual direction from the subject's eye to the blackboard was at $1 \mathrm{~m}$.

\section{Experiment 1}

Pitched-from-vertical stimulus condition. In the first condition of the experiment, the pitched-from-vertical two-line stimulus was employed (Figure 2a). The two phosphorescent strips were placed symmetrically on opposite sides of the subject's midsagittal plane, each set at a horizontal eccentricity of $25^{\circ}$; the horizontal separation between the two lines at true eye level was thus $50^{\circ}$. The midpoint of each of the two vertical lines was set at the subject's true eye level.

Experimental measurements of VPEL were made with the plane containing the vertical two-line visual field pitched at each of seven different angles: pitched "topbackward" at $-30^{\circ},-20^{\circ}$, or $-10^{\circ}$, erect at $0^{\circ}$, or pitched "topforward" at $10^{\circ}, 20^{\circ}$, or $30^{\circ}$. This resulted in a symmetrical change in the visual angle extent of each line with pitch: the line subtended $57.0^{\circ}, 62.3^{\circ}, 65.3^{\circ}$, and $66.5^{\circ}$ at pitches of $\pm 30^{\circ}, \pm 20^{\circ}, \pm 10^{\circ}$, and $0^{\circ}$, respectively. Since the influence of each line on VPEL had virtually saturated at lengths considerably shorter than $50^{\circ}$ (Li \& Matin, 1991b; Matin \& Li, 1994b), this variation in extent with pitch was of no significance.

A vertical setting of a red circular target, approximately $10^{\prime}$ visual angle diameter, was employed as a measure of VPEL. This was obtained in the following way: A $1.0-\mathrm{cm}$-wide slot was cut in the center of the vertical dimension of one of the opaque blackboards (the one employed to vary pitch) and a sheet of translucent white plastic was attached to the blackboard's rear surface to cover the opening. The target was projected onto the rear surface of the translucent plastic from the optically attenuated output of a 0.5 $\mathrm{mW} \mathrm{He}-\mathrm{Ne}$ laser that was mounted horizontally on a vertical track of a rack-and-pinion arrangement attached to a mobile relay rack. The entire arrangement was positioned closely behind the black- board. The laser's horizontal beam was itself completely invisible under all conditions. The experimenter was able to adjust the elevation of the laser-generated target by moving the laser along the vertical track.

Slanted-from-frontal horizontal line stimulus condition. The two-line stimulus was rotated by $90^{\circ}$ in a plane parallel to the plane of the blackboard in order to provide the visual field for the second condition of the experiment (Figure $2 \mathrm{~b}$ ). The two horizontal strips were symmetrically placed $25^{\circ}$ above and below the subject's true eye level. The midpoint of each of the two horizontal lines intersected the subject's midsagittal plane.

The plane containing the horizontal two-line stimulus was set at each of seven angles of slant relative to the midsagittal plane of the subject. The seven angles were $-30^{\circ},-20^{\circ}$, and $-10^{\circ}$, with the right side of the two-line stimulus rotated away from the subject ("rightbackward," counterclockwise as viewed from above), $0^{\circ}$ (frontoparallel), and $10^{\circ}, 20^{\circ}$, or $30^{\circ}$ "rightforward" (clockwise). The plane containing the horizontal two-line visual field was always erect. As in the case of pitch, this resulted in a symmetrical change in the visual angle extent of each line with slant: the line subtended $57.0^{\circ}, 62.3^{\circ}, 65.3^{\circ}$, and $66.5^{\circ}$ at slants of $\pm 30^{\circ}, \pm 20^{\circ}$, $\pm 10^{\circ}$, and $0^{\circ}$, respectively.

A 3-cm-wide strip of white tape was attached horizontally to the other blackboard (the one employed to vary slant) at the height of the subject's true eye level (midway between the two phosphorescent strips). The laser, mounted on the mobile relay rack, was now placed behind and to the side of the subject, and its beam projected onto the white tape; the laser was rotated around a vertical axis in order to change the location of its projection on the tape. Settings of the projection of the laser target along the horizontal were employed as measures of VPSA.

\section{Experiment 2}

Experiment 2 employed the slanted-from-frontal horizontal two-line stimulus only. The experiment was identical to the slanted-from-frontal horizontal line condition of Experiment 1 with only one exception. The two lines were set $15^{\circ}$ above and 


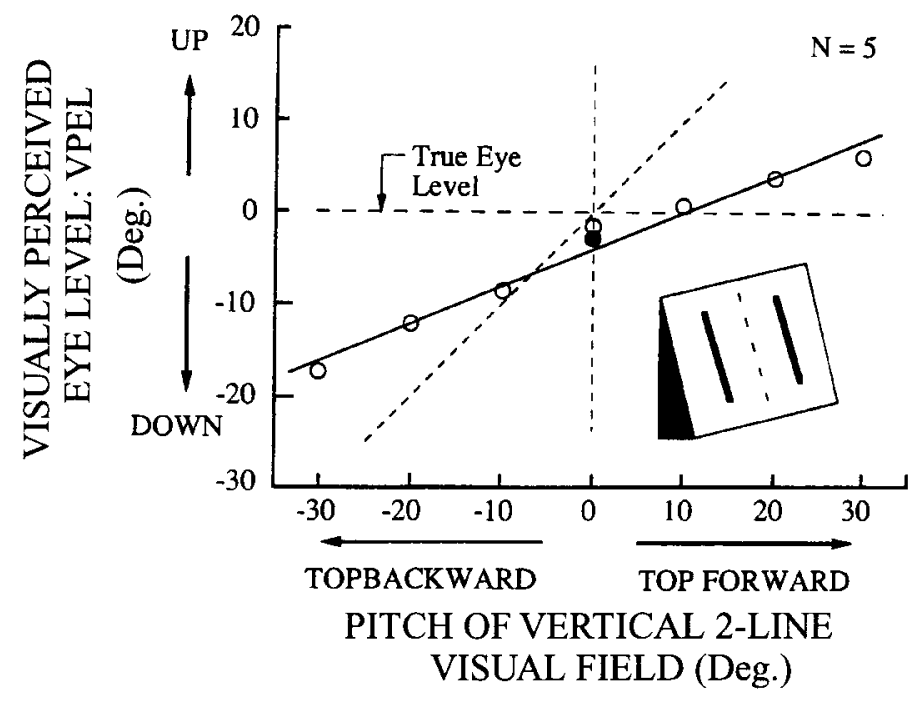

(a)

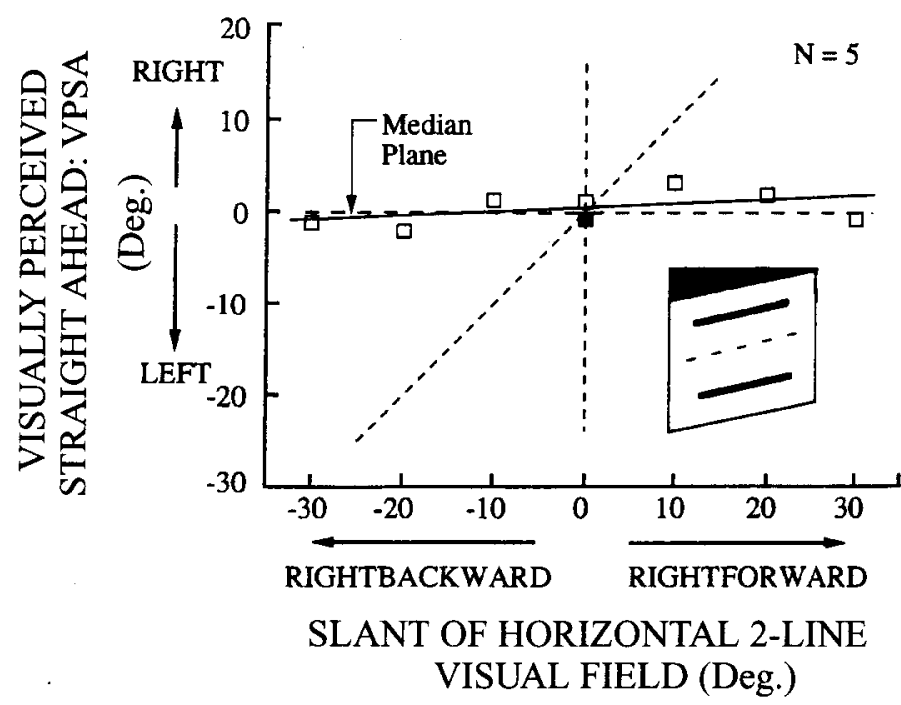

(b)

Figure 3. (a) Visually perceived eye level (VPEL) is plotted as a function of the pitch of the vertical two-line visual field. Each data point is the average VPEL value of 5 subjects. The horizontal dashed line at ordinate zero represents true eye level for all angles of pitch. A VPEL setting at the level of the normal from the eye to the plane of the two-line stimulus would equal the pitch of the plane containing the two-line stimulus (dashed line with slope of +1.00 ). The solid straight line has a slope of +0.40 and is the line of best fit (least squares) to the data. (b) Visually perceived straight ahead (VPSA) is plotted as a function of the slant of the horizontal two-line visual field. Each data point is the average value of five subjects. The horizontal dashed line at ordinate zero represents a VPSA setting at the median plane for all angles of slant. A VPSA setting at the level of the normal from the eye to the plane of the two-line stimulus would equal the slant of the plane containing the two-line stimulus (dashed line with slope of +1.00 ). The solid straight line is the least squares line of best fit to the data and has a slope of +0.05 . In each panel, the filled point was measured in darkness without the presence of the two-line stimulus. See Tables 1 and 2 for numerical VPEL and VPSA values and best fitting parameters for individual subjects.

below true eye level instead of the $25^{\circ}$ above and below that was employed in Experiment 1.

\section{Experiment 3}

All four horizontal lines used in Experiments 1 and 2 were displayed simultaneously. Thus, the visual field consisted of four horizontal lines, with two of them symmetrically placed $15^{\circ}$ above and below true eye level and an additional two identical lines sym- metrically placed $10^{\circ}$ more peripherally $\left(25^{\circ}\right.$ above and below true eye level). The same procedure was followed as that in Experiments 1 and 2 .

\section{Experiment 4}

In Experiment 4, the two vertical lines were employed in their erect orientation, as in Experiment 1. In this experiment. however instead of being pitched, the plane containing the two lines was 
Table 1

VPEL Values and Best-Fitting Parameters for Pitched-From-Vertical Two-Line Stimulus

\begin{tabular}{|c|c|c|c|c|c|c|c|c|c|c|c|c|c|}
\hline \multirow[b]{4}{*}{ Subject } & \multicolumn{8}{|c|}{ Pitched Visual Field } & & & & & \\
\hline & \multicolumn{3}{|c|}{ Topbackward } & \multirow{3}{*}{$\begin{array}{c}\frac{\text { Erect }}{0^{\circ}} \\
\text { VPEL }\end{array}$} & \multicolumn{3}{|c|}{ Topforward } & \multirow{3}{*}{$\begin{array}{l}\text { Avg. } \\
S D\end{array}$} & \multicolumn{3}{|c|}{ Dark Field } & \multirow{2}{*}{\multicolumn{2}{|c|}{$\begin{array}{c}\text { Best-Fit } \\
\text { Straight Line }\end{array}$}} \\
\hline & \multirow{2}{*}{$\begin{array}{l}-30^{\circ} \\
\text { VPEL }\end{array}$} & \multirow{2}{*}{$\begin{array}{l}-20^{\circ} \\
\text { VPEL } \\
\end{array}$} & \multirow{2}{*}{$\begin{array}{l}-10^{\circ} \\
\text { VPEL }\end{array}$} & & \multirow{2}{*}{$\begin{array}{c}10^{\circ} \\
\text { VPEL }\end{array}$} & \multirow{2}{*}{$\begin{array}{c}20^{\circ} \\
\text { VPEL }\end{array}$} & \multirow{2}{*}{$\begin{array}{c}30^{\circ} \\
\text { VPEL }\end{array}$} & & \multirow{2}{*}{$\begin{array}{l}\text { Before } \\
\text { VPEL }\end{array}$} & \multirow{2}{*}{$\begin{array}{l}\text { After } \\
\text { VPEL }\end{array}$} & \multirow{2}{*}{$\overline{\text { Avg. }}$} & & \\
\hline & & & & & & & & & & & & Slope & $y$-intercept \\
\hline A.D. & $15.4 \mathrm{D}$ & $10.0 \mathrm{D}$ & 4.7D & $0.5 \mathrm{D}$ & $2.5 \mathrm{U}$ & $2.7 \mathrm{U}$ & $5.6 \mathrm{U}$ & 0.6 & $1.3 \mathrm{U}$ & $3.2 \mathrm{D}$ & 0.6 & +0.34 & $2.8 \mathrm{D}$ \\
\hline L.F. & $18.2 \mathrm{D}$ & $15.8 \mathrm{D}$ & 9.9D & $0.4 \mathrm{D}$ & $0.1 \mathrm{U}$ & $4.0 \mathrm{U}$ & $3.8 \mathrm{U}$ & 1.1 & $1.2 \mathrm{D}$ & $1.8 \mathrm{U}$ & 1.1 & +0.41 & $5.1 \mathrm{D}$ \\
\hline L.M. & $18.6 \mathrm{D}$ & $14.1 \mathrm{D}$ & $8.5 \mathrm{D}$ & $3.8 \mathrm{D}$ & $1.4 \mathrm{U}$ & $5.7 \mathrm{U}$ & $8.1 \mathrm{U}$ & 0.5 & $4.2 \mathrm{D}$ & $5.0 \mathrm{D}$ & 1.1 & +0.46 & $4.3 \mathrm{D}$ \\
\hline R.Z. & $16.2 \mathrm{D}$ & $7.4 \mathrm{D}$ & $10.5 \mathrm{D}$ & $2.3 \mathrm{U}$ & $1.4 \mathrm{U}$ & $2.3 \mathrm{U}$ & $6.5 \mathrm{U}$ & 1.0 & $3.7 \mathrm{D}$ & $4.4 \mathrm{D}$ & 1.0 & +0.36 & $3.8 \mathrm{D}$ \\
\hline W.L. & $17.7 \mathrm{D}$ & $13.7 \mathrm{D}$ & $9.1 \mathrm{D}$ & $5.5 \mathrm{D}$ & $1.6 \mathrm{D}$ & $3.9 \mathrm{U}$ & $6.4 \mathrm{U}$ & 0.5 & $4.7 \mathrm{D}$ & $4.4 \mathrm{D}$ & 0.8 & +0.41 & $5.3 \mathrm{D}$ \\
\hline Mean & $17.2 \mathrm{D}$ & $12.2 \mathrm{D}$ & $8.5 \mathrm{D}$ & $1.6 \mathrm{D}$ & $0.8 \mathrm{U}$ & $3.7 \mathrm{U}$ & $6.1 \mathrm{U}$ & 0.7 & $2.5 \mathrm{D}$ & $3.0 \mathrm{D}$ & 0.9 & +0.40 & $4.3 \mathrm{D}$ \\
\hline
\end{tabular}

Note-VPEL $=$ visually perceived eye level; $\mathrm{D}=$ below true eye level; $\mathrm{U}=$ above true eye level.

Table 2

VPSA Values and Best-Fitting Parameters for Slanted-From-Frontal Horizontal Two-Line Stimulus (Two Lines Separated by $50^{\circ}$ )

\begin{tabular}{|c|c|c|c|c|c|c|c|c|c|c|c|c|c|}
\hline \multirow[b]{4}{*}{ Subject } & \multicolumn{8}{|c|}{ Slanted Visual Field } & & & & & \\
\hline & \multicolumn{3}{|c|}{ Rightbackward } & \multirow{3}{*}{$\begin{array}{c}\text { Frontal } \\
0^{\circ} \\
\text { VPSA }\end{array}$} & \multicolumn{3}{|c|}{ Rightforward } & \multirow{3}{*}{$\begin{array}{l}\text { Avg. } \\
S D\end{array}$} & \multicolumn{3}{|c|}{ Dark Field } & \multirow{2}{*}{\multicolumn{2}{|c|}{$\begin{array}{c}\text { Best-Fit } \\
\text { Straight Line }\end{array}$}} \\
\hline & $-30^{\circ}$ & $-20^{\circ}$ & $-10^{\circ}$ & & $10^{\circ}$ & $20^{\circ}$ & $30^{\circ}$ & & Before & After & Avg. & & \\
\hline & VPSA & VPSA & VPSA & & VPSA & VPSA & VPSA & & VPSA & VPSA & $S D$ & Slope & $y$-intercept \\
\hline A.D. & $5.4 \mathrm{R}$ & $1.1 \mathrm{R}$ & $4.4 \mathrm{R}$ & $0.1 \mathrm{R}$ & $2.7 \mathrm{R}$ & $6.1 \mathrm{R}$ & $3.9 \mathrm{R}$ & 1.0 & $3.8 \mathrm{~L}$ & $4.0 \mathrm{~L}$ & 0.6 & +0.01 & $3.4 \mathrm{R}$ \\
\hline L.F. & $0.1 \mathrm{R}$ & $0.5 \mathrm{~L}$ & $3.5 \mathrm{R}$ & $0.3 \mathrm{R}$ & $0.9 \mathrm{~L}$ & $1.8 \mathrm{R}$ & $0.9 \mathrm{R}$ & 1.3 & $0.3 \mathrm{~L}$ & $1.1 \mathrm{~L}$ & 1.2 & +0.01 & $0.8 \mathrm{R}$ \\
\hline L.M. & $5.8 \mathrm{~L}$ & $2.8 \mathrm{~L}$ & $2.6 \mathrm{R}$ & $0.1 \mathrm{~L}$ & $7.1 \mathrm{R}$ & $2.6 \mathrm{~L}$ & $2.9 \mathrm{~L}$ & 1.3 & $0.8 \mathrm{R}$ & $1.2 \mathrm{R}$ & 1.4 & +0.05 & $0.7 \mathrm{~L}$ \\
\hline R.Z. & $2.2 \mathrm{~L}$ & $4.1 \mathrm{~L}$ & $1.0 \mathrm{~L}$ & $3.1 \mathrm{R}$ & $4.1 \mathrm{R}$ & $2.3 R$ & $1.3 \mathrm{~L}$ & 1.8 & $3.7 \mathrm{~L}$ & $1.7 \mathrm{~L}$ & 1.1 & +0.07 & $0.1 \mathrm{R}$ \\
\hline W.L. & $3.5 \mathrm{~L}$ & $3.9 \mathrm{~L}$ & $3.2 \mathrm{~L}$ & $2.3 \mathrm{R}$ & $2.9 \mathrm{R}$ & $1.3 \mathrm{R}$ & $4.5 \mathrm{~L}$ & 0.8 & $2.4 \mathrm{R}$ & $2.9 \mathrm{R}$ & 0.6 & +0.05 & $1.2 \mathrm{~L}$ \\
\hline Mean & $1.2 \mathrm{~L}$ & $2.0 \mathrm{~L}$ & $1.3 \mathrm{R}$ & $1.1 \mathrm{R}$ & $3.2 \mathrm{R}$ & $1.8 \mathrm{R}$ & $0.8 \mathrm{~L}$ & 1.2 & $0.9 \mathrm{~L}$ & $0.5 \mathrm{~L}$ & 1.1 & +0.04 & $0.5 \mathrm{R}$ \\
\hline
\end{tabular}

Note-VPSA = visually perceived straight ahead; $\mathrm{L}=$ left of median plane; $\mathrm{R}=$ right of median plane.

subjected to the same series of slants employed in Experiments 1-3 with horizontal lines. The same procedure was followed in measuring VPSA as in the three previous experiments.

\section{Procedure}

The same procedure was followed in all four experiments. The subject sat on a stool facing the blackboard, with head position and viewing distance determined by a chinrest attached to the stool. The display was viewed with the right eye; the left eye was occluded by an eye patch. The visual field was completely dark, ${ }^{3}$ with the exception of the lines and the laser target described above.

In Experiment 1, all measurements on a given subject with the pitched-from-vertical two-line stimulus were made in a single session. Four VPEL measurements were made at each of the pitch angles before proceeding to a different pitch. The order in which the seven pitch angles were examined was different for each of the 5 subjects and was determined by a quasirandom process. All measurements with the slanted-from-frontal two-line stimulus were made in a second session. The same procedure was followed in a second session with the horizontal two-line slanted-from-frontal stimulus. Four VPSA measurements were made at each of the slant angles before proceeding to a different slant. The order in which the seven angles of slant were examined was different for each of the 5 subjects and was also different from the order employed for the examination of pitch; determination of slant order was again by a quasirandom process.

In the sessions in which pitch was manipulated, four VPEL settings were made with the field in total darkness at the beginning and end of every session. In the sessions in which slant was manipulated, four VPSA settings were made with the field in total darkness at the beginning and end of every session.

The procedure in Experiments 2, 3, and 4 was the same as the second session in Experiment 1 involving the slant manipulation.

A method of adjustment with hunting was employed for setting both VPEL and VPSA. The subject was instructed to fixate the red target at the beginning of each measurement. For the VPEL measurements with the pitched-from-vertical two-line stimulus, a trial began with the subject's eyes closed. The experimenter set the laser target either far above or far below the region of uncertainty and instructed the subject to open his/her eyes, fixate the target, and report whether the target needed to be moved up or down in order to appear at VPEL. The subject immediately closed his/her eyes, whereupon the experimenter reset the elevation of the target by a variable amount and again instructed the subject to open his/her eyes and report on the elevation of the target relative to VPEL. This sequence was repeated until the subject indicated that the target was at VPEL. A similar procedure was followed in the session with measurements of VPSA to different slants. Here, the horizontal position, instead of the elevation, of the laser-generated target was manipulated by the experimenter and the subject reported on the relation of the target's horizontal location relative to VPSA.

\section{Subjects}

Five subjects were employed in Experiment 1. Two of these were the authors; the other 3 were Columbia University undergraduates, who were naive regarding the purposes of the experiment. Three subjects participated in the Experiments 2, 3, and 4. For W.L., more than 2 years had intervened between the measurements in Experiments 1 and 2; for L.F. and A.D., about 3 weeks had intervened. Experiment 3 was run approximately 2 weeks following the completion of Experiment 2; Experiment 4 was run approximately 2 weeks following the completion of Experiment 3.

\section{RESULTS}

The results of Experiment 1 are summarized in Figure 3 and in Tables 1 and 2; the results of Experiments 2, 3, and 4 are summarized in Figure 4 and in Tables 3, 


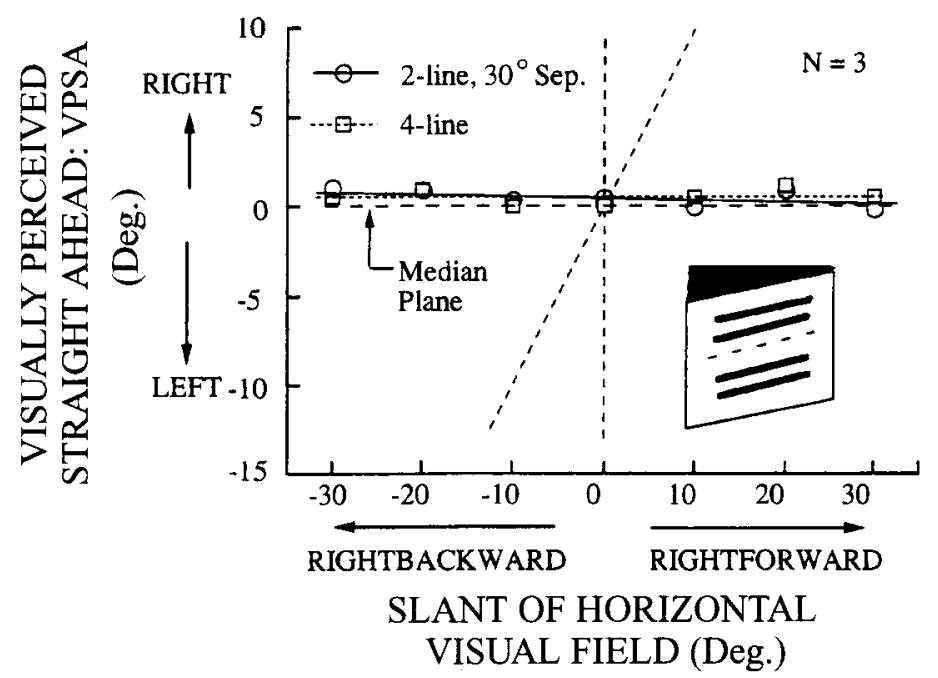

(a)

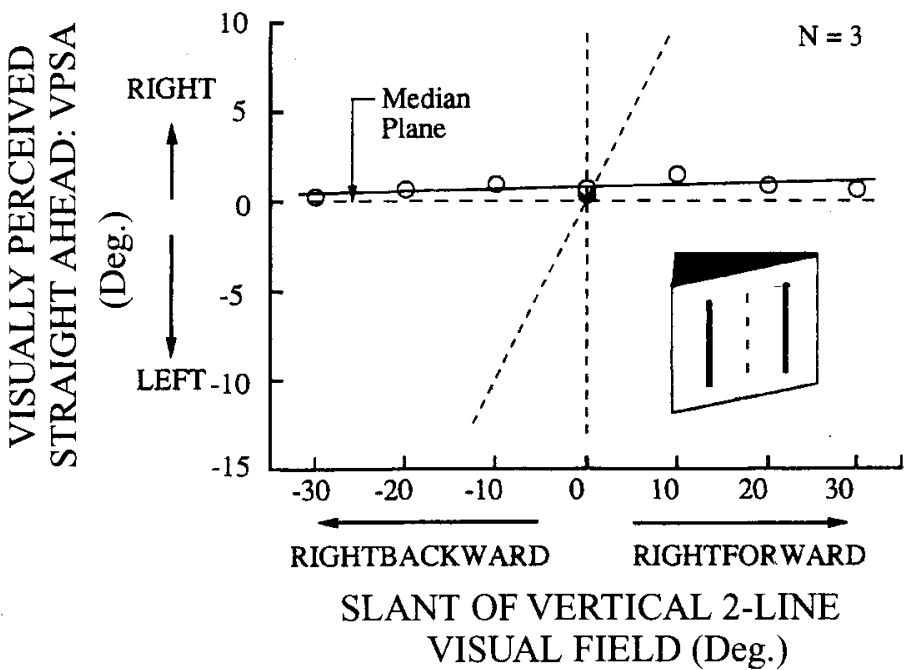

(b)

Figure 4. (a) Visually perceived straight ahead (VPSA) is plotted as a function of the slant of the horizontal two-line visual field (Experiment $2,30^{\circ}$ separation, circles) and four-line visual field (Experiment 3, squares). Each data point is the average value of 3 subjects. The horizontal dashed line at ordinate zero represents a VPSA setting at the median plane for all angles of slant. A VPSA setting on the normal from the eye to the plane of the two-line stimulus would equal the slant of the plane containing the two-line stimulus (diagonal dashed line; note magnification of ordinate scale relative to scale for abscissa). The solid and dotted straight lines are the lines of best fit (least squares) to the data for the horizontal twoline visual field and for the horizontal four-line visual field, respectively. They both have slopes close to 0.00 . The dark VPSA values are not displayed; they completely overlap the VPSA values with the line stimuli displayed there. See Tables 3 and 4 for numerical VPSA values and best fitting parameters for individual subjects. (b) VPSA is plotted as a function of the slant of the vertical two-line stimulus ( $50^{\circ}$ separation). Each data point is the average value of 3 subjects. The average slope of the VPEL-versus-slant function is +0.01. See Table 5 for numerical VPSA values and best-fitting parameters for individual subjects.

4, and 5. Each VPEL value (Table 1) and each VPSA value (Tables 2, 3, 4, and 5) for each subject is the average of the four measurements made at a single orientation or in darkness. The average $S D$ displayed in each table for an individual subject was obtained by first calculating the $S D$ of the four measurements at each of the seven orientations and then averaging the seven values. Each average $S D$ tabled for the dark field is the average of the two separate $S D$ s for measurements at the beginning and the end of the experimental session. A best-fitting straight line (least squares criterion) was fitted to the VPEL and VPSA values for each subject 
in each of the experiments. The slopes and $y$-intercept values for these lines are given in the tables along with the VPELs or VPSAs. A linear best fit was also applied to the values averaged across subjects for each experimental condition; the results of these fits are plotted in Figures 3 and 4.

\section{VPEL With a Pitched-From-Vertical Two-Line Visual Field}

VPEL increased linearly with the pitch of the two-line stimulus, although the slopes of the best-fitting straight lines differed somewhat among the 5 subjects (Figure 3a, Table 1). This is in agreement with the results reported earlier by Matin, Fox, and Doktorsky (1987) and by Matin and Li (1989b, 1992b, 1994a, 1994b, in press). Although the slopes of the best-fitting straight lines are smaller than those in some of the previous reports for the average values ( 0.40 in Experiment 1 vs. 0.56 and 0.52 in the two experiments of the previous report), this difference was predicted from our analysis ( $\mathrm{Li} \&$ Matin, 1990) of the influence of some parameters of the stimulus presentation that differed between the two experiments. ${ }^{4}$

\section{VPSA With a Slanted-From-Frontal Horizontal Two-Line Visual Field}

The change in VPSA with slant was small and nonmonotonic, with the average slope equal to 0.04 (Figure $3 b$, Table 2). There does not appear to be any basis for concluding that the slope reflects anything but random variation from a 0.00 mean. With average slopes approximately at 0.01 (Figure 4a, Tables 3 and 4), the results of Experiment 2, in which the slanted-from-frontal stimulus was placed less peripherally, and the results of Experiment 3 , with the use of a four-line stimulus, are even clearer regarding the lack of influence of the slanted-fromfrontal stimulus on VPSA.

\section{VPSA With a Slanted-From-Frontal Vertical Two-Line Visual Field}

The slope of the VPSA-versus-slant function of Experiment 4 was flat for each of the 3 subjects; the average for the 3 subjects was 0.01 (Figure $4 b$, Table 5).

\section{Dark VPELs and VPSAs}

The dark VPEL values were below true eye level in 8 of the 10 sets of measurements on the 5 subjects in

Table 3

VPSA Values and Best-Fitting Parameters for Slanted-From-Frontal Horizontal Two-Line Stimulus (Two Lines Separated by 30 ) in Experiment 2

\begin{tabular}{|c|c|c|c|c|c|c|c|c|c|c|c|c|c|}
\hline \multirow[b]{4}{*}{ Subject } & \multicolumn{8}{|c|}{ Slanted Visual Field } & & & & & \\
\hline & \multicolumn{3}{|c|}{ Rightbackward } & \multirow{3}{*}{$\begin{array}{c}\frac{\text { Frontal }}{0^{\circ}} \\
\text { VPSA }\end{array}$} & \multicolumn{3}{|c|}{ Rightforward } & \multirow{3}{*}{$\begin{array}{l}\text { Avg. } \\
S D\end{array}$} & \multicolumn{3}{|c|}{ Dark Field } & \multirow{2}{*}{\multicolumn{2}{|c|}{$\begin{array}{c}\text { Best-Fit } \\
\text { Straight Line }\end{array}$}} \\
\hline & $-30^{\circ}$ & $-20^{\circ}$ & $-10^{\circ}$ & & $10^{\circ}$ & $20^{\circ}$ & $30^{\circ}$ & & Before & After & Avg. & & \\
\hline & VPSA & VPSA & VPSA & & VPSA & VPSA & VPSA & & VPSA & VPSA & $S D$ & Slope & $y$-intercept \\
\hline$\overline{\text { A.D. }}$ & $3.9 \mathrm{R}$ & $1.7 \mathrm{R}$ & $1.8 \mathrm{R}$ & $0.6 \mathrm{R}$ & $0.4 \mathrm{~L}$ & 3.3R & $0.4 \mathrm{R}$ & 0.5 & $0.2 \mathrm{~L}$ & $0.2 \mathrm{R}$ & 1.2 & -0.03 & $1.6 \mathrm{R}$ \\
\hline L.F. & $0.3 \mathrm{R}$ & $2.2 \mathrm{R}$ & $1.5 \mathrm{R}$ & $1.2 \mathrm{R}$ & $0.9 \mathrm{R}$ & $0.2 \mathrm{R}$ & $0.4 \mathrm{R}$ & 1.5 & $3.4 \mathrm{R}$ & $1.5 \mathrm{R}$ & 1.0 & -0.01 & $1.0 \mathrm{R}$ \\
\hline W.L. & $1.2 \mathrm{~L}$ & $1.5 \mathrm{~L}$ & $2.8 \mathrm{~L}$ & $0.2 \mathrm{~L}$ & $0.8 \mathrm{~L}$ & $1.1 \mathrm{~L}$ & $1.6 \mathrm{~L}$ & 1.3 & $1.9 \mathrm{~L}$ & $2.0 \mathrm{~L}$ & 1.7 & +0.01 & $1.3 \mathrm{~L}$ \\
\hline Mean & $1.0 \mathrm{R}$ & $0.8 \mathrm{R}$ & $0.2 \mathrm{R}$ & $0.5 \mathrm{R}$ & $0.1 \mathrm{~L}$ & $0.8 \mathrm{R}$ & $0.3 \mathrm{~L}$ & 1.1 & $0.4 \mathrm{R}$ & $0.1 \mathrm{~L}$ & 1.3 & -0.01 & $0.4 \mathrm{R}$ \\
\hline
\end{tabular}

Table 4

VPSA Values and Best-Fitting Parameters for Slanted-From-Frontal Horizontal Four-Line Stimulus in Experiment 3

\begin{tabular}{|c|c|c|c|c|c|c|c|c|c|c|c|c|c|}
\hline \multirow[b]{4}{*}{ Subject } & \multicolumn{8}{|c|}{ Slanted Visual Field } & & & & & \\
\hline & \multicolumn{3}{|c|}{ Rightbackward } & Frontal & \multicolumn{3}{|c|}{ Rightforward } & \multirow{3}{*}{$\begin{array}{l}\text { Avg. } \\
S D\end{array}$} & \multicolumn{3}{|c|}{ Dark Field } & \multirow{2}{*}{\multicolumn{2}{|c|}{$\begin{array}{c}\text { Best-Fit } \\
\text { Straight Line }\end{array}$}} \\
\hline & \multirow{2}{*}{$\begin{array}{l}-30^{\circ} \\
\text { VPSA }\end{array}$} & \multirow{2}{*}{$\begin{array}{r}-20^{\circ} \\
\text { VPSA }\end{array}$} & \multirow{2}{*}{$\begin{array}{r}-10^{\circ} \\
\text { VPSA }\end{array}$} & \multirow{2}{*}{$\begin{array}{c}0^{\circ} \\
\text { VPSA }\end{array}$} & \multirow{2}{*}{$\begin{array}{c}10^{\circ} \\
\text { VPSA }\end{array}$} & \multirow{2}{*}{$\begin{array}{c}20^{\circ} \\
\text { VPSA }\end{array}$} & \multirow{2}{*}{$\begin{array}{c}30^{\circ} \\
\text { VPSA }\end{array}$} & & \multirow{2}{*}{$\begin{array}{l}\text { Before } \\
\text { VPSA }\end{array}$} & \multirow{2}{*}{$\begin{array}{l}\text { After } \\
\text { VPSA } \\
\end{array}$} & \multirow{2}{*}{$\begin{array}{l}\text { Avg. } \\
S D\end{array}$} & & \\
\hline & & & & & & & & & & & & Slope & $y$-intercept \\
\hline A.D. & $1.5 \mathrm{R}$ & $0.6 \mathrm{R}$ & $1.0 \mathrm{R}$ & $0.6 \mathrm{R}$ & $0.8 \mathrm{~L}$ & $1.2 \mathrm{R}$ & $0.9 \mathrm{R}$ & 0.4 & $0.5 \mathrm{R}$ & $1.9 \mathrm{R}$ & 0.9 & -0.01 & $0.7 \mathrm{R}$ \\
\hline L.F. & $2.4 \mathrm{R}$ & $4.0 \mathrm{R}$ & $1.9 \mathrm{R}$ & $0.4 \mathrm{R}$ & $1.5 \mathrm{R}$ & $3.7 \mathrm{R}$ & $3.0 \mathrm{R}$ & 0.3 & $1.0 \mathrm{R}$ & $1.8 \mathrm{R}$ & 1.3 & 0.00 & $2.4 \mathrm{R}$ \\
\hline W.L. & $2.5 \mathrm{~L}$ & $2.1 \mathrm{~L}$ & $2.8 \mathrm{~L}$ & $1.0 \mathrm{~L}$ & $0.9 \mathrm{R}$ & $1.5 \mathrm{~L}$ & $2.3 \mathrm{~L}$ & 0.6 & $2.3 \mathrm{~L}$ & $2.6 \mathrm{~L}$ & 1.2 & +0.02 & $1.6 \mathrm{~L}$ \\
\hline Mean & $0.5 \mathrm{R}$ & $0.8 \mathrm{R}$ & 0.0 & 0.0 & $0.5 \mathrm{R}$ & $1.1 \mathrm{R}$ & $0.5 \mathrm{R}$ & 0.5 & $0.3 \mathrm{~L}$ & $0.4 \mathrm{R}$ & 1.1 & +0.003 & $0.5 \mathrm{R}$ \\
\hline
\end{tabular}

Table 5

VPSA Values and Best-Fitting Parameters for Slanted-From-Frontal Vertical Two-Line Stimulus in Experiment 4

\begin{tabular}{|c|c|c|c|c|c|c|c|c|c|c|c|c|c|}
\hline \multirow[b]{4}{*}{ Subject } & \multicolumn{8}{|c|}{ Slanted Visual Field } & & & & & \\
\hline & \multicolumn{3}{|c|}{ Rightbackward } & Frontal & \multicolumn{3}{|c|}{ Rightforward } & \multirow{3}{*}{$\begin{array}{l}\text { Avg. } \\
S D\end{array}$} & \multicolumn{3}{|c|}{ Dark Field } & \multirow{2}{*}{\multicolumn{2}{|c|}{$\begin{array}{c}\text { Best-Fit } \\
\text { Straight Line }\end{array}$}} \\
\hline & $-30^{\circ}$ & $-20^{\circ}$ & $-10^{\circ}$ & $\overline{0^{\circ}}$ & $10^{\circ}$ & $20^{\circ}$ & $30^{\circ}$ & & Before & After & Avg. & & \\
\hline & VPSA & VPSA & VPSA & VPSA & VPSA & VPSA & VPSA & & VPSA & VPSA & $S D$ & Slope & $y$-intercept \\
\hline A.D. & $0.9 \mathrm{R}$ & $0.6 \mathrm{R}$ & $0.8 \mathrm{R}$ & $1.4 \mathrm{R}$ & $2.2 \mathrm{R}$ & $2.1 \mathrm{R}$ & $0.2 \mathrm{R}$ & 0.8 & $1.1 \mathrm{R}$ & $0.2 \mathrm{R}$ & 0.9 & +0.009 & $1.2 \mathrm{R}$ \\
\hline L.F. & $0.3 \mathrm{R}$ & $0.1 \mathrm{R}$ & $2.0 \mathrm{R}$ & $0.6 \mathrm{~L}$ & $0.9 \mathrm{R}$ & $0.6 \mathrm{R}$ & $1.4 \mathrm{R}$ & 1.1 & $0.3 \mathrm{~L}$ & $0.8 \mathrm{~L}$ & 2.3 & +0.012 & $0.7 \mathrm{R}$ \\
\hline W.L. & $0.6 \mathrm{~L}$ & $1.2 \mathrm{R}$ & 0.0 & $1.2 \mathrm{R}$ & $1.2 \mathrm{R}$ & $0.1 \mathrm{R}$ & $0.5 \mathrm{R}$ & 0.7 & $0.1 \mathrm{~L}$ & $1.9 \mathrm{R}$ & 1.2 & +0.008 & $0.5 \mathrm{R}$ \\
\hline Mean & $0.2 \mathrm{R}$ & $0.6 \mathrm{R}$ & $0.9 \mathrm{R}$ & $0.7 \mathrm{R}$ & $1.4 \mathrm{R}$ & $0.9 \mathrm{R}$ & $0.7 \mathrm{R}$ & 0.9 & $0.2 \mathrm{R}$ & $0.4 \mathrm{R}$ & 1.5 & +0.010 & $0.8 \mathrm{R}$ \\
\hline
\end{tabular}

Note-For Tables 3, 4, and 5, VPSA = visually perceived straight ahead; $L=$ left of median plane; $R=$ right of median plane. 
Table 1 and averaged $2.8^{\circ}$, a result that is in agreement with earlier reports (Matin \& Fox, 1986, 1989, 1990; Matin \& Li, 1989b, 1992b; Stoper \& Cohen, 1986) where the large majority of dark VPELs also fell below true eye level. No systematic trend across subjects is visible between the values taken at the beginning and end of the sessions, suggesting that the factors determining VPELs were in a reasonably steady state throughout the session.

The average VPSA setting in darkness was quite close to the median plane in each of Experiments 1-4, with the average value across subjects in each of the eight cases being less than $1^{\circ}$. There was no indication of any systematic trend.

\section{Response Variability}

The average $S D$ of the four VPEL settings across the seven pitches and 5 subjects was $0.7^{\circ}$, with no systematic variations with pitch. Although the average $S D$ in the dark across the 5 subjects was slightly larger than the average in the presence of the two-line stimulus, a result that is in line with those in previous experiments (Matin $\& \mathrm{Li}, 1992 \mathrm{~b}$ ), the difference was too small to be significant. There was no consistent trend in the difference in variability of the VPSA settings between darkness and in the presence of the two-line stimulus.

\section{DISCUSSION}

The principal finding of this study is that although the pitched-from-vertical two-line stimulus produces a substantial influence on VPEL that is linear with pitch magnitude as previously reported, variation of the slant of the horizontal two-line stimulus does not influence VPSA. Reducing the vertical separation between the two horizontal lines or increasing the number of horizontal lines simultaneously presented did not change the result. Systematically varying the slant of the vertical two-line stimulus, whose pitch influenced VPEL so markedly, did not produce any influence on VPSA. Although we do not yet have a full explanation of the difference between the influence of pitch on VPEL and the lack of influence of slant of either horizontal or vertical lines on VPSA, we are able to describe several factors that are likely to play a role in the explanation and to rule out a number of potential sources of influence.

\section{Differences in the Stimulus Bases for VPEL and VPSA: Relations to Gravity}

Some basis for the present difference in influences of visual field on VPEL and VPSA is likely to derive from the very different relations to gravity of the two dimensions within which the VPSA and VPEL discriminations are made. Whereas gravity polarizes the dimension of elevation and determines the orientation of the plane containing the observer's true eye level, there is no polarizer external to the observer that makes unique a vertical plane corresponding to the observer's midsagittal plane. Since the horizontal dimension is unpolarized with respect to gravity, gravity cannot provide information that would be useful for the VPSA discrimination, whereas the VPEL discrimination is meaningful only in relation to the direction of gravity. ${ }^{5}$ Changing the physical orientation of an individual in space modifies the spatial relation of true eye level and the physical direction of the median plane to the physical environment differently. These differences are likely to have consequences for the ways in which VPEL and VPSA are influenced by the visual environment. As a result, the influences from the visual field and the body-referenced mechanism are likely to be weighted very differently in determining VPEL and VPSA in the presence of a rotated visual field.

True eye level is the plane perpendicular to the direction of gravity through the nodal point of the eye. When the eye's height is changed through changes in posture. such as head movements or change from a reclining to a standing position, changes in the physical height of true eye level exactly parallel the changes in height of the eye. Since gravity is ever-present in a terrestrial environment, it is available to provide an ever-present environmental "fiducial marker" for VPEL in both darkness and illumination. In darkness, the utilization of the gravitoinertial stimulus is sufficiently sensitive, in combination with other components of the body-referenced mechanism, so that VPEL settings are made with a reliability of $1^{\circ}$ and an accuracy that is rarely worse than $6^{\circ}$ (Hoppeler, 1913; Li \& Matin, 1990, 1991b; MacDougall, 1903; Matin \& Fox, 1986, 1989; Matin \& Li, 1989b, 1990, 1991, 1992b; Matin et al., 1982; Matin et al., 1983; Sharp, 1934; Stoper \& Cohen, 1986). In normal illuminated environments, both natural and man-made, a large proportion of the surfaces and objects within the normal range of gaze are erect, resulting in an influence on the elevation of VPEL from the visual field that is concordant with the influence from gravity. But there is no environmental marker analogous to gravity with an invariant relation to a particular direction in the visual field that could be employed for processing VPSA. Instead the setting of VPSA relates to a particular plane only within the body. Since the orientation of this plane in space changes with changes in body orientation around a vertical axis, its relation to any particular erect plane, and thus to the set of all erect planes, would have a very large random component.

There is a second difference in the way in which true eye level and the physical direction of the median plane are related to the physical environment. Head rotations in the vertical dimension (i.e., pitching the head on the neck around a horizontal axis in the frontal plane) change the linear height of true eye level minimally. Thus, changes in head pitch have only very small influences on the angular elevation of objects relative to true eye level. But head-and-body rotations in the horizontal dimension (i.e., around a vertical axis) produce large changes of the physical orientation of the median plane 
with an angular extent equal to the angle of head-andbody rotation. Coupled with the random relation of the median plane to the slant of planes in the visual environment noted above, this suggests that VPSA would need to be relatively independent of visual stimulation to be at all useful as a basis for egocentric localization and/or orientation and would rely heavily on the bodyreferenced mechanism. On the other hand, even large vertical head rotations produce relatively small changes in the elevation of objects relative to true eye level. Coupled with the relatively stable relation of true eye level to the orientation of planes in the normal environment, this suggests that useful information relative to VPEL could be obtained from the environment under most conditions. The results of the present experiments support these considerations regarding the relative importance of external and internal factors on VPEL and VPSA.

\section{Differences Regarding Extraretinal Eye Position Information for VPSA and VPEL}

As noted in the introduction, for the erect individual, the body-referenced mechanism for egocentric localization requires inputs from three sources: EEPI, extraretinal head orientation information, and information regarding retinal location of the target. The input from each of the three must signal orientation in the vertical dimension for VPEL, whereas it must signal orientation in the horizontal dimension for VPSA. Perceptual constancy of VPEL and VPSA in darkness (Matin et al., 1982) requires a particular kind of involvement of EEPI: The EEPI signals would have to tend to restore VPEL and VPSA to the same physical location at which they are set for viewing in primary position.

The lack of symmetry in the influence of the visual field for VPEL and VPSA raises the possibility that the contribution of EEPI to egocentric localization and orientation regarding vertical eye position may be substantially modified as a result of the presence of an input from the visual field but that the contribution of EEPI regarding horizontal eye position is not. An implication of such modification for VPEL has been examined by measuring eye position with a scleral search coil. In the experiment, an observer was asked to direct his/her gaze in the horizontal visual direction while viewing a visual field containing only the pitched-from-vertical two-line stimulus in darkness in the absence of the laser target. The observer turned his/her eye to the same direction as the visible laser target that he/she had set to VPEL on another set of trials. The ocular deviations from true eye position were systematic with the pitch of the two-line stimulus and reached error magnitudes as large as $18^{\circ}$ (Li \& Matin, 1993c; also see Cohen, Ebenholtz, \& Linder, 1993). The simplest interpretation of these results is that the signal that is employed to control eye position is also employed to control egocentric localization and that the influence of the visual field acts to bias EEPI. ${ }^{6}$

Thus, the failure of the change in slant of the horizontal two-line stimulus to have any influence on VPSA suggests the following three alternatives: (1) the horizontal two-line stimulus does not contain aspects of visual stimulation appropriate to generate a systematic influence on VPSA, (2) EEPI for horizontal eye position is more resistant to misregistration as a result of influences from the visual field, and (3) the relation to the direction of gravity is a component that is important in promoting the influence of a visual field on egocentric localization; the failure for VPSA is related to the fact that the latter component was missing.

\section{Insignificance of Several Retinal Image Gradients}

The normal line of visual direction from the eye to the stimulus plane is shifted downward with increasing "topbackward" pitch and leftward with increasing "leftforward" slant (Figure 1). The separation between the retinal images of the two parallel lines decreases with increasing distance of the line segments from the normal; this is a result of the increasing distance from the subject's eye. We have referred to this variation as monocular biconvergence perspective (MBP) and described its properties quantitatively (Matin \& Li, 1992b). Although we were unable to conclude that MBP did not play a role in the variation of VPEL with the pitch of the two-line stimulus, we were able to conclude that MBP's presence was not necessary for the influence of the two-line stimulus to be manifested on VPEL and that the influence of the two-line stimulus on VPEL was based on the retinal orientation of each of the individual lines (Matin $\& \mathrm{Li}$, 1992b, 1994a). Since MBP for the horizontal slantedfrom-frontal two-line stimulus varies with slant, just as it varies with pitch for the pitched-from-vertical twoline stimulus, if MBP was capable of exerting a significant influence on spatial localization generally, we would expect to have obtained a significant influence of slant on VPSA. The fact that we did not obtain such a result suggests that MBP was uninvolved in the outcome of the present experiments.

Both the width of the retinal image and the quantity of luminous flux in a line's cross section decrease monotonically with distance from the image point corresponding to the point on the line intersected by the normal from the eye to the line. In addition, lens accommodation can only be best for a single object distance from the eye, resulting in a distance-dependent blur gradient along the line. Since the location of the normal on the stimulus lines changes systematically with pitch and slant, these gradients might be thought to contribute to the difference between the ways in which VPEL and VPSA are influenced by pitch and slant, respectively. However, it is clear that this is not so. We have previously shown that these gradients are not involved in the influence of visual pitch on VPEL for the pitched-fromvertical lines (Matin \& Li, 1992a, 1992b, 1994a). We arrived at that conclusion in part by calculations that showed that the blur variation was the dominant influence on the width gradient but that the net gradient was only $2.9 \mathrm{sec}$ of arc per degree of visual angle over the $38^{\circ}$ 
segment of the line from the normal to the top of the line and an even shallower $0.85 \mathrm{sec}$ per degree from the normal to the bottom of the line in the erect case. Since the lines were presented at a horizontal eccentricity of $25^{\circ}$ where acuity is near its poorest, a gradient this shallow is highly unlikely to influence spatial discriminations at all. The flux variations are similarly small and even less likely to be involved in the discriminations. Similar values of the gradients pertain for the stimuli in both the vertical and the horizontal two-line visual fields in the present experiments, and it would thus be difficult to believe that the gradients play any significant role in the difference in results between the two orientations. It is also worth noting that variation of the steepness of the gradient of width of the retinal image of the line by pilocarpine-produced pupil reduction was without effect on VPEL (Matin \& Li, 1994a). The insignificance of these gradients is further indicated by the fact that a pitched-from-vertical line from a pitched-only plane and an oblique line from an erect plane stimulating the same retinal locus have identical influences on VPEL, although the point on the retinal image corresponding to the stimulus point that intersects the normal line of visual direction is different in the two cases (Matin \& Li, 1990, 1992a).

\section{Insignificance of Stimulus Distance and Binocular Vision}

As mentioned above, the influence on VPEL is identical whether the lines stimulating particular retinal regions arise from pitched-from-vertical lines in pitchedonly planes or from oblique lines in erect planes (Matin $\& \mathrm{Li}, 1990,1992 \mathrm{a})$. Thus, the particular way in which a stimulus line extends into the third dimension is irrelevant for the VPEL discrimination. Although a similar experiment has not yet been carried out regarding the VPSA discrimination, there is no reason to believe that an influence on VPSA will be obtained from oblique lines in a frontoparallel plane that is different from that obtained from the retinally identical lines in slantedfrom-frontal planes employed in the present experiments.

In the present experiments, the subjects viewed monocularly, and so information from binocular vision could not have contributed to the difference in result between VPEL and VPSA. Previous experiments have also demonstrated that binocular cues have no significant influence on VPEL (Matin \& Li, 1992a, 1992b; Matin, Li, \& Doktorsky, 1988; Stoper \& Cohen, 1989). Since horizontal lines are much less useful sources for stereocues than are vertical lines generally, no difference in result would be expected if the present experiments were to be repeated with binocular vision.

\section{Closing Comments}

Observers viewing an illuminated visual field through wedge prisms make VPSA errors that are considerably less than the optical deviation produced by the prism; however, in darkness, the perceptual errors equal the full prismatic deviation. For this to happen, some aspects of a slanted-from-frontal visual stimulus would have to be capable of generating an influence on VPSA. However, the present results and the above discussion appear to lead us to the conclusion that whatever those visual stimulus aspects might be, they are not contained in the slanted-from-frontal horizontal stimulus. ${ }^{7}$ But things are more complex, and such a simple conclusion is ruled out by the results of subsequent experiments (Dallal, Li, \& Matin, 1993). In those experiments, we found that for observers lying on their sides (median plane horizontal), either the systematic rotation of a vertical two-line stimulus around a horizontal axis or the systematic rotation of a horizontal two-line stimulus around a vertical axis in the frontal plane of the observer leads to systematic mislocalizations of magnitudes that are in ranges similar to those we describe herein for VPELs with erect subjects. This implies that the failure of the slantedfrom-frontal horizontal two-line stimulus to generate a systematic influence on VPSA in the present experiments is not a simple consequence of the inadequacy of the variation in orientation of the retinal image of the horizontal two-line stimulus around a vertical axis. ${ }^{8}$ Influences of other parameters must be involved, and the problem has taken on a level of complication that requires still further work for a resolution to be reached.

\section{REFERENCES}

Cohen, M. M., Ebenholtz, S. M., \& Linder, B. J. (1993). Effects of optical pitch on oculomotor control and perceived elevation. Bulletin of the Psychonomic Society, 31, 357. (Abstract)

Dallat, N., Li, W., \& Matin, L. (1993). Visually perceived eye level and straight ahead: Influences from visual field pitch, visual field slant, observer orientation, and gravity. Eastern Psychological Association, 64, 42. (Abstract)

HopPELER, P. (1913). Über den Stellungsfaktor der Sehrichtungen; eine experimentelle Studie [An experimental study of eye level]. Zeitschrift für Psychologie, 66, 249-262.

Kleinhans, J. L. (1970). Perception of spatial orientation in sloped. slanted, and tilted visual fields. Unpublished doctoral dissertation, Rutgers University, New Brunswick, NJ.

Li, W., \& Matin, L. (1990). Perceived eye level: Sensitivity to pitch of a vertical 2 -line stimulus grows with eccentricity but is biased by elevation. Investigative Ophthalmology \& Visual Science, 31(4, Suppl.), 84

LI, W., \& MATIN, L. (1991 a). The influence of visual pitch on visually perceived eye level is spatiotopic. Bulletin of the Psychonomic Society, 29, 488. (Abstract)

LI, W., \& Matin, L. (1991b). Spatial summation of influences on visually perceived eye level from a single variably-pitched 1-line stimulus. Investigative Ophthalmology \& Visual Science, 32, 1272.

LI, W., \& MATIN, L. (1992). Linear averaging of the influences from 2 -lines of different pitch or obliquity on visually perceived eye level. Investigative Ophthalmology \& Visual Science, 33, 1154.

LI, W., \& Matin, L. (1993a). Eye \& head position, visual pitch, and perceived eye level. Investigative Ophthalmology \& Visual Science, 34, 1311 .

Li, W., \& Matin, L. (1993b). Prism-generated and real pitch influence egocentric localization similarity; prism-generated and real slant don't. Bulletin of the Psychonomic Society, 31, 367. (Abstract)

LI, W., \& MATIN, L. (1993c). The same extraretinal eye position information is involved in egocentric localization (VPEL) and control of eye position: Identical influences by visual pitch. Unpublished manuscript.

MacDougall, R. (1903). The subjective horizon. Psychological Review Monograph Supplements, $4(1$, Whole No. 17), 145-166. 
Matin, L. (1986). Visual localization and eye movements. In K. Boff, L. Kaufman, \& J. Thomas (Eds.), Handbook of perception and human performance (Vol. 1, ch. 20, pp. 20-1-20-45). New York: Wiley.

Matin, L., \& Fox, C. R. (1986). Perceived eye level: Elevation jointly determined by visual field pitch, EEPI, and gravity. Investigative Ophthalmology \& Visual Science, 27(3, Suppl.), 333.

MatiN, L., \& Fox, C. R. (1989). Visually perceived eye level and perceived elevation of objects: Linearly additive influences from visual field pitch and from gravity. Vision Research, 29, 315-324.

Matin, L., \& Fox, C. R. (1990). "Visually perceived eye level and perceived elevation of objects: Linearly additive influences from visual field pitch and from gravity": Corrigenda. Vision Research, 30, I.

MatiN, L., Fox, C. R., \& DokTorsky, Y. (1987). How high is up? Investigative Ophthalmology \& Visual Science, 28(3, Suppl.), 300.

MATIN, L., \& LI, W. (1989a). Linear summation of visual influences on perceived eye level. Journal of the Optical Society of America, Technical Digest Series, Annual Meeting, 18, 161.

Matin, L., \& LI, W. (1989b). A single pitched line in darkness controls elevation of visually perceived eye level. Investigative Ophthalmology \& Visual Science, 30(3, Suppl.), 506.

MATIN, L., \& LI, W. (1990). Identical effects on perceived eye level by oblique lines in erect planes and pitched-from-vertical lines in pitched planes. Investigative Ophthalmology \& Visual Science, 31, 328.

Matin, L., \& LI, W. (1991). Separate mechanisms for perceived eye level and perceived vertical: Dissection by pitch and roll of a 2-line stimulus. Investigative Ophthalmology \& Visual Science, 32, 900.

Matin, L., \& Li, W. (1992a). Mislocalizations of visual elevation and visual vertical induced by visual pitch: The great circle model. Annals of the New York Academy of Sciences, 656, 242-265.

Matin, L., \& LI, W. (1992b). Visually perceived eye level: Changes induced by a pitched-from-vertical 2-line visual field. Journal of Experimental Psychology: Human Perception \& Performance, 18, 257-289.

Matin, L., \& Li, W. (1994a). The influence of the orientation of a stationary single line in darkness on the visual perception of eye level. Vision Research, 34, 311-330.

Matin, L., \& LI, W. (1994b). Spatial summation among parallel lines across wide separations $\left(50^{\circ}\right)$ : Spatial localization and the great circle model. Vision Research, 34, 2577-2598.

Matin, L., \& LI, W. (in press). Mirror symmetry and parallelism: Two opposite rules for the identity transform in space perception and their unified treatment by the great circle model. Spatial Vision.

MatIN, L., LI, W., \& DoKTORSKY, Y. (1988). Immediate prismatic correction: Its basis in monocular biconvergence perspective. Investigative Ophthalmology \& Visual Science, 29(3, Supp.), 409.

Matin, L., Picoult, E., Stevens, J. K., Edwards, M. W., Jr., YounG, D., \& MACARTHUR, R. (1982). Oculoparalytic illusion: Visual-field dependent mislocalizations by humans partially paralyzed with curare. Science, 216, 198-201.

Matin, L., Stevens, J. K. \& Picoult, E. (1983). Perceptual consequences of experimental extraocular muscle paralysis. In A. Hein \& M. Jeannerod (Eds.), Spatially Oriented Behavior (ch. 14, pp. 243262). New York: Springer.

RoCK, I., GOLDBERG, J., \& MACK, A. (1966). Immediate correction and adaptation based on viewing a prismatically displaced scene. Perception \& Psychophysics, 1, 351-354.

SHARP, W. L. (1934). An experimental study concerning visual localization in the horizontal plane. Journal of Experimental Psychology, 17, 787-797.

STOPER, A. E., \& COHEN, M. M. (1986). Judgments of eye level in light and in darkness. Perception \& Psychophysics, 40, 311-316.

STOPER, A. E., \& COHEN, M. M. (1989). Effect of structured visual environments on apparent eye level. Perception \& Psychophysics, 46, 469-475.

\section{NOTES}

1. We employ symmetry in one of its common meanings here to refer to corresponding properties of visual projection resulting from rotation of a vertical two-line stimulus around a horizontal axis and rotation of a horizontal two-line stimulus around a vertical axis (Figure 1) and their similar perceptual consequences. However, an anonymous referee noted that there may be some ambiguity in the use of the term in the present context and suggested that we spell out the meaning (as above), although the referee states, "Unfortunately, I don't think a better term exists: terms like similarity, equivalence, correspondence or parallel don't do the concept justice, either." In the Method section, and in a subsequent note, we also employ symmetry to refer to bilateral symmetry. However, no confusion should result.

2. Pitch refers to rotation of the visual field around a horizontal axis in a frontal plane of the observer. Although slant has been employed with many different meanings by others in other contexts, in this article it refers only to rotation of the erect plane around a vertical axis in the midsagittal plane.

3. The surroundings were invisible to observers, who were dark adapted for a minimum of $30 \mathrm{~min}$. Although the EG\&G photometerradiometer (Model 550) is capable of reading values as low as $1 \times$ $10^{-5} \mathrm{fL}$ - close to the dark-adapted rod absolute threshold-zero readings were obtained at all locations on the blackboard and side walls of the room in which the experiment was conducted.

4. In the present experiment, the height of the two-line pitchedfrom-vertical stimulus was constant since the pitch axis was in the stimulus plane, whereas in the earlier experiments the two-line stimulus was elevated systematically, with pitch to values as large as $43.7^{\circ}$ over $50^{\circ}$ pitch range. This difference was a result of the fact that in the earlier experiments the two-line stimulus was mounted on the pitchroom wall, whose pitch axis was $26.5 \mathrm{in}$. above the floor and located near the subject. However, since the subject's eye was reset to $1 \mathrm{~m}$ from the normal under each condition of pitch, the effective axis for rotation was maintained in the axis through the subject's eye lying in the frontoparallel plane. But the change in the height of the pitch axis in the stimulus plane produced a systematic $10 \%$ change in the elevation of the $y$-intercept of the VPEL-versus-pitch function with no change in slope (Li \& Matin, 1990). Thus, the stimulus change in the pitchroom is equivalent to a combination of two components: (1) a change in pitch around an axis fixed in height, and (2) a change in height of the axis of rotation. Consequently, a slope of +0.40 - the present result with the pitch axis height fixed-would be expected to be transformed into a slope of +0.473 with the two-line stimulus in the pitchroom. Given the differences in subject populations, this prediction compares favorably with the values of +0.52 and +0.56 obtained previously with the twoline stimulus in the pitchroom.

5. Two things lead us to the belief that gravity is critical for the VPEL discrimination in the present experiments and that the discrimination was in fact being made relative to the direction of gravity: (1) The subjects were instructed to set the laser target in the horizontal visual direction (i.e., the direction that is perpendicular to gravity) when setting to VPEL. (2) In an experiment in which the subject's head orientation was varied systematically over $\mathrm{a} \pm 30^{\circ}$ range around a horizontal axis in the frontoparallel plane, VPEL measured with a vertical two-line visual field remained nearly constant, thus retaining an essentially fixed relation to gravity (Li \& Matin, 1991a, 1993a).

6 . However, these results do not force the conclusion that EEPI has itself been biased. Two alternatives remain possible: (1) the influence of the pitched visual field biases the mechanism responsible for VPEL directly without prior action on EEPI, and (2) the pitched visual field biases extraretinal head orientation information (EHOI). If EHOI was biased around a horizontal axis in the frontal plane and EEPI remained unbiased, the setting of the eye to feel horizontal would need to be turned from true eye level in the opposite direction and by an amount equal to the EHOI bias. Even if the action of the pitched visual field does modify the contribution of EEPI to the VPEL discrimination, the site of the modification remains uncertain: The action could modify EEPI itself or reduce the weighting of the EEPI signal in relation to the influence of the visual field by a mechanism that combines both (Matin \& Fox, 1986, 1989; Matin \& Li, 1992a, 1992b).

7. An anonymous referee has called our attention to an otherwise unpublished dissertation (Kleinhans, 1970), which contained two experiments (Experiments 1 and 3 ) in which egocentric localization was measured. In that Experiment 1, subjects viewed the inside of an $18 \times$ $18 \times 21$ in. box that was pitched and/or slanted, and the subject reported eye level and straight ahead by calling out numbers on vertical and horizontal numbered scales inside the box, respectively. Kleinhans 
concluded (pp. ii-iii) that "Both phenomenal directions were shifted from the veridical toward parallelism with the framework ... Eye-level judgments were affected approximately twice as much as were straight-ahead judgments." Although the values listed in Kleinhans's Tables 1 and 2 (pp. 47-48) do indicate a systematic influence of pitch on VPEL and point to the possibility of an influence of slant on VPSA that is $1 / 4$ (not $1 / 2$, as Kleinhans states) as large as the influence of pitch on VPEL, there are confounds in the experimental design (including confounds between pitch and slant), errors of calculation in the tables on which the conclusions are based (a full $10 \%$ of the 140 nonzero values in his Table 2 are in error, some large), and difficulties with the analysis presented--all of which make questionable any interpretation of what is presented. In his Experiment 3, in which the subject viewed a 3 -ft cubic wooden framework outlined with $1 / 4$-in.wide luminous tape, the major confounds appear to have been separated: The subject set a target light to VPEL or to VPSA with the frame either pitched or slanted, respectively. The VPEL values are not unlike those we measure herein. Although a small and inconsistent influence of slant on VPSA was measured with an asymmetrical stimulus similar to the one Kleinhans had employed in his Experiment 1, this influ- ence was completely eliminated with a symmetrical stimulus in which the axis of rotation was on the rear wall of the configuration, an arrangement intended to eliminate the influence of lateral displacement (the physical stimulus was not planar; thus, the retinal configuration was not symmetrical relative to true eye level or the median plane for pitch or slant, respectively, as in the experiments we describe herein).

8 . Since the relation of the horizontal two-line visual stimulus to gravity is unchanged when its orientation around a vertical axis is varied, the result also implies that the subject lying on his/her side employs a reference for the discrimination that is dependent on the orientation of his/her own body within the horizontal plane. Although such a reference may also be involved in the VPEL discrimination for the erect subject (for which the variation of the visual stimulus is around the vertical axis relative to the body), the experimental results referred to in Note 5 above make it clear that a substantial portion of the reference must be related to the direction of gravity.

(Manuscript received January 24, 1994; revision accepted for publication August 10, 1994.) 